\title{
Prestígio e hierarquia escolar: estudo de caso sobre diferenças entre escolas em uma rede municipal $^{*}$
}

\author{
Marcio da Costa
}

Universidade Federal do Rio de Janeiro, Faculdade de Educação

Este trabalho explora diferenças entre escolas públicas integrantes da mesma rede de ensino. Faz parte de um projeto de investigação que busca compreender os elementos que conferem diferenciação a estabelecimentos de ensino que, submetidos à mesma autoridade e às mesmas regras, integrando os mesmos sistemas e dispondo de recursos equivalentes, apresentam considerável disparidade em muitos aspectos e gozam de reputações claramente opostas. Nosso esforço, ancorado em literatura de pesquisa voltada à diferenciação do efeito das escolas (school matters, school effects) e à efetividade escolar (school effectiveness), compõe-se do estudo de caso em seis escolas municipais da cidade do Rio de Janeiro, organizadas em pares, em três diferentes regiões geográficas - e socioeconômicas - da cidade. Cada par foi escolhido procurando contemplar escolas que usufruem prestígio claramente oposto, localizadas em áreas próximas, podendo atender a populações assemelhadas.

* Trabalho desenvolvido com auxílio do Conselho Nacional de Desenvolvimento Científico e Tecnológico (CNPq), por meio de bolsa de produtividade e financiamento à pesquisa.
Não encontramos, até o momento, estudos que adotassem o mesmo tipo de critério de escolha e reconhecemos a possível fluidez do conceito de "prestígio escolar". No entanto, em estudo anterior ${ }^{1}$ observamos nítida diferenciação traçada pelas burocracias educacionais - seja em níveis administrativos intermediários seja no corpo funcional das escolas -e, principalmente, pela população de alunos e seus parentes quanto a uma intrincada teia hierárquica composta pelo sistema público em estudo. Na pesquisa anterior, realizada em 23 escolas públicas e privadas, saltavam distinções socioeconômicas entre os alunos de escolas das mesmas redes, mas, sobretudo, ficavam evidentes ambientes $^{2}$ escolares em grande contraste, algumas vezes contrariando uma idéia pouco questionada que

${ }^{1}$ Educação e exclusão social; o sagrado sob ameaça. Pesquisa financiada pelo CNPq que pode ter alguns de seus resultados encontrados em Costa e Koslinski (2006).

${ }^{2}$ Por ora, usaremos o termo ambiente como a composição de muitos elementos que criam padrões de relacionamento, possibilidades de ação educacional, sentimentos entre os membros da comunidade escolar. 
atribuiria ao nível socioeconômico do alunado essa configuração escolar. Seria difícil imaginar que uma das sociedades mais desiguais do mundo, com um padrão urbano-industrial de desenvolvimento médio, não gerasse complexas hierarquias em seus sistemas públicos de ensino. Todavia, a força de que ainda desfrutam modelos interpretativos dicotômicos limita a atenção sobre esse fenômeno, que deve estar associado a estruturas de fortalecimento da desigualdade social. Assim, diante de esquemas conceituais calcados nas oposições explorados $x$ exploradores, pobres $x$ ricos, público $x$ privado em sociologia da educação, no Brasil, são raros os mergulhos em processos de hierarquização mais complexos, porém não menos relevantes. Talvez estudos como o que temos realizado auxiliem a compreender a crítica situação de um amplo sistema educacional que logrou incorporar recentemente a quase totalidade de seu público potencial ao nível fundamental de ensino, mas que guarda abismos em todos os níveis escolares e, conseqüentemente, nas oportunidades de integração socioprofissional de gerações à sociedade em geral.

Em busca da compreensão desse fenômeno - o prestígio escolar -, por considerá-lo possivelmente explicativo de diferenças no desenvolvimento escolar do alunado, procuramos por literatura que nos auxiliasse nessa empreitada. Alguns estudos brasileiros têm-se dedicado a compreender processos escolares vinculados à formação de elites. ${ }^{3}$ Entretanto, nosso foco está alguns "degraus" abaixo desse patamar de extração social, ainda que, sociologicamente, os alunos das escolas públicas de boa reputação possam ser considerados um certo tipo de elite diante de seus pares.

O conceito de elite aqui utilizado recebe definição mais elástica do que na sociologia política clássica. Enquanto nela elites são pensadas sempre em relação ao exercício, homogeneidade e usufruto do poder, adotamos uma caracterização mais abrangente, sociológica.

${ }^{3}$ Destacam-se os trabalhos de grupos liderados pelas professoras Maria Alice Nogueira (1998, 2005), Maria Alice Nogueira e Ana Almeida (2002), Maria Alice Nogueira e Ramon Abreu (2004) e Zaia Brandão (2006).
Pensamos elites como detentoras de oportunidades e recursos pouco acessíveis às "massas", em disputas pelo controle de tais recursos, os quais conferem oportunidades vantajosas de poder, prestígio e riqueza. Se nos ativermos às assim chamadas teorias das elites, estaremos talvez mais calcados na tradição que vai de Robert Dahl a Vilfredo Pareto do que na que liga Wright Mills a Gaetano Mosca, dado que enfatizamos as disputas por espaços sociais reservados. ${ }^{4}$ Nesse sentido, a contenda pelo acesso a recursos escolares superiores, ainda que entre segmentos sociais que não podem ser bem enquadrados na caracterização clássica de elite, pode configurar a busca de um recurso escasso (escola de boa qualidade) altamente relevante para as aspirações futuras de seus postulantes. Alguns relatos de campo, entrevistas ou mesmo o resultado do survey aplicado sugerem que essas escolas diferenciadas não apenas ampliam as chances competitivas de seus egressos, como também o próprio acesso a elas - ao menos em parte-depende da posse de recursos sociais diferenciados, o que as enquadraria como espaços de formação e reprodução de elites. ${ }^{5}$

Investigações em países mais desenvolvidos mais recentemente, também no Brasil - têm buscado destrinchar as effective schools, ou, por outra vertente, a efetividade escolar (school effectiveness). De maneira geral, a intenção é conhecer as realidades de escolas que podem ser consideradas bem-sucedidas junto a seus alunos em condições socioeconômicas desfavoráveis.

Basicamente, duas grandes linhas analíticas se destacam: as explicações centradas na "liderança escolar" e aquelas referidas ao "clima escolar". Não se trata de construções conceituais antagônicas, mas de diferenças de matiz. A primeira acentua características

${ }^{4}$ A esse respeito, ver: Dahl (1997). Também em Max Weber (1992) pode ser encontrada a idéia de uma disputa por posições em um mercado restrito.

${ }^{5}$ Claro que, se pensamos em uma gradação nas elites, não corroborando os modelos dicotômicos que apenas contrapõem elites/massas, somos influenciados pela noção de competição ou "circulação" de elites, o que conduz a uma concepção de elites como grupos não-homogêneos. 
individualizadas (como a resiliência) que imprimem às trajetórias dos estabelecimentos escolares pontos de inflexão e curvas ascendentes. A segunda busca dissecar elementos que comporiam quadros em que as escolas se constituem em alavancas virtuosas para seus alunos, sendo a liderança um desses aspectos. A composição social do alunado, os padrões de relacionamento entre os diversos atores, a interação paisescola, a configuração do corpo docente, os recursos disponíveis e seu uso efetivo e a gestão/organização do trabalho educacional são outras dimensões potencialmente explicativas dos quadros observados que compõem o sintético conceito de "clima escolar".

Os estudos têm tratado o desempenho escolar como desfecho fundamental de investigação e elemento diferenciador das realidades escolares. Nosso trabalho volta-se a algo menos passível de mensuração: o prestígio escolar. Consideramos, a priori, que tal prestígio deve estar em forte medida associado ao desempenho dos alunos em termos de aprendizado. Deve-se, porém, ter cuidado em tomar esses dois elementos como equivalentes. Afinal, o desempenho em testes padronizados é uma medida momentânea ainda que passível de ser aplicada e acompanhada longitudinalmente -, ao passo que a reputação de uma escola é algo construído ao longo de um tempo não curto e sujeito a outros elementos constitutivos que não apenas o score em avaliações de grande escala. Há, ainda, o fato de que os sistemas de avaliação educacional no Brasil são relativamente recentes e ainda não permitem abordagem segura no nível de estabelecimento escolar. ${ }^{6}$ Em contrapartida, ainda que seja talvez seu resultado mais relevante, não é apenas aprendizado escolar o que uma escola promove. ${ }^{7}$

${ }^{6}$ Apenas a partir de 2005, com a criação do sistema denominado Prova Brasil, passou a ser possível agregação de dados de desempenho, medido por meio de testes padronizados, no nível de escola. No entanto, além de muito recente, esse sistema ainda tem adesão voluntária por parte das escolas e seus microdados não estavam disponíveis quando da redação deste artigo.

${ }^{7}$ Há, contudo, dificuldades relevantes na identificação e mensuração dos efeitos escolares sobre a aquisição de outros
Imaginávamos que seria possível criar uma medida bastante significativa do prestígio das escolas dessa rede municipal junto a seu público. Era - ao menos até 2005 - prática usual na rede municipal do Rio de Janeiro que, ao final de um ano letivo, pais e responsáveis por alunos das turmas de $4^{\mathrm{a}}$ série do ensino fundamental pudessem optar por escolas nas quais gostariam que seus filhos fossem matriculados na $5^{\mathrm{a}}$ série. A passagem da $4^{\mathrm{a}}$ para a $5^{\mathrm{a}}$ série é um demarcador no sistema escolar brasileiro e, particularmente na rede municipal do Rio de Janeiro. ${ }^{8}$ A tendência é de que as escolas atendam a um ou outro segmento, sendo essa uma política implantada pela Secretaria Municipal de Educação. Por razões metodológicas, ${ }^{9}$ optamos por realizar o estudo apenas em escolas que atendessem da $5^{\mathrm{a}}$ a $8^{\mathrm{a}}$ série, limite superior de atendimento municipal no Rio de Janeiro e em quase todo o Brasil, quando os alunos passam então da rede municipal para a rede estadual. Para nossa frustração, o acesso às listas tríplices de escolhas dos pais ${ }^{10}$ nos foi

recursos que não aqueles passíveis de testagem, como as disciplinas curriculares. A esse respeito, ver Sorensen e Morgan (2000).

${ }^{8}$ Desde a realização desta pesquisa, a organização dos níveis da educação fundamental no Rio de Janeiro passou por grande mudança, introduzindo-se os ciclos além do quinto ano de escolaridade, compreendendo todo o ensino fundamental. Porém, no período da pesquisa, ainda não se encontravam em vigor tais medidas, alcançando a política de organização em ciclos apenas o primeiro segmento do ensino fundamental.

${ }^{9}$ Considerando de grande importância ouvir as opiniões do alunado, optamos por escolas de séries mais adiantadas do ensino fundamental. Além disso, essas são séries mais complexas em sua organização, o que permite maior diversidade de situações escolares. Em acréscimo, após alguns anos de escolaridade, as diferenças com as quais pretendemos trabalhar já estão supostamente cristalizadas de forma mais nítida.

${ }^{10}$ Ao final da $4{ }^{\mathrm{a}}$ série, como a maioria das escolas aí encerra seu atendimento, era prática usual que os pais fossem chamados a manifestar sua preferência para transferência dos filhos à série subseqüente em alguma escola municipal das imediações. Essa manifestação era feita por meio de um formulário no qual eram 
terminantemente negado pelas instâncias da Secretaria Municipal de Educação. ${ }^{11}$

Ficamos, portanto, restritos a uma escolha de escolas a partir de informações difusas e indicações colhidas - não sem dificuldade - entre conversas com funcionários da administração educacional. Nossa pergunta básica para seleção dos casos era: que escolas de uma determinada região apresentam grande/pequena demanda e são consideradas destaques positivos/negativos? Tais escolhas se revelaram, ainda que colhidas de maneira menos precisa do que pretendíamos, bastante satisfatórias para nossas intenções de estudo, atendendo plenamente à proposta de estudarmos escolas com características internas bem distintas e reputações opostas.

Para desenvolvimento dos estudos de casos, como de hábito, adotamos procedimentos diversos de coleta e tratamento de informações. Foram cerca de quatro meses de presença nas escolas, realizando entrevistas e observações com roteiros semi-estruturados. Além disso, dois surveys foram realizados, com o universo dos alunos e professores das seis escolas. Pretendíamos ainda realizar um survey com amostra de pais e responsáveis, mas encontramos fortes barreiras em algumas das escolas para que pudéssemos cumprir tal intento, ${ }^{12}$ além de algumas dificuldades operacionais.

indicadas três escolas com o segundo segmento do ensino fundamental, em ordem de preferência.

${ }^{11}$ Essa negativa é uma questão da maior importância, não apenas pela evidente inclinação anti-republicana que enseja, mas pelas suspeitas que suscita quanto à alocação de vagas na rede municipal do Rio de Janeiro. Estamos buscando sistematizar elementos que complementem a abordagem desse processo. Artigo especificamente destinado a tratar essa diferença de oportunidades de acesso já se encontra em elaboração.

${ }^{12} \mathrm{O}$ acesso aos pais tem sido uma dificuldade para a pesquisa, dado que algumas escolas dificultam ao máximo tal contato, recusando fornecer alguns nomes para entrevistas e dado que não costumam promover atividades que atraiam pais/responsáveis. Dispomos de algumas entrevistas, mas provavelmente com pais mais próximos da vida escolar o que, em algumas situações, significa identificados com a direção das escolas em questão.
O presente trabalho, de caráter descritivo, dedicar-se-á a apresentar os resultados do survey com alunos, mas tais resultados estarão entremeados por observações extraídas das entrevistas e visitas regulares às escolas por parte da equipe de pesquisa. Estamos convictos de que os resultados apresentados neste artigo, embora preliminares, são bastante expressivos e, infelizmente, retratam uma profunda desigualdade escolar entrelaçada à desigualdade social e de aptidões.

\section{Pequena narrativa sobre as escolas estudadas}

As seis escolas que foram palco de nosso estudo receberão as denominações de $\mathrm{N}+, \mathrm{N}-, \mathrm{T}+, \mathrm{T}-, \mathrm{S}+\mathrm{e}$ S-. Tal denominação contempla dois tipos de hierarquia. A primeira diz respeito a zonas da cidade. N, T e S são abreviaturas de Zonas Norte, Tijuca e Sul. Há uma clara distinção ascendente de $\mathrm{N}$ a $\mathrm{S}$ em termos socioeconômicos; a região $\mathrm{T}$ ocupa posição intermediária nessa classificação. Os resultados do survey endossam cabalmente essa escolha a priori. A essa hierarquia geográfico-socioeconômica conjuga-se uma classificação do prestígio das escolas, expresso pelo sinal + ou -.

Dessa forma, a maior parte dos dados aqui expostos buscará descrever informações expressas na forma de diversas variáveis, organizadas em blocos (informações socioeconômicas; perfil familiar; trajetória escolar; hábitos e práticas sociais; interação e suporte família-escola; aspirações e expectativas; avaliação da escola e processos de escolha da escola), segundo essa organização geográfica, socioeconômica e de prestígio no interior da rede escolar mais abrangente. Eventualmente, outras relações poderão ser exploradas, para além das diferenças de área e prestígio, mas, por força de limites e foco deste artigo, essas outras relações deverão aparecer apenas de forma ocasional. ${ }^{13}$

${ }^{13}$ Outros trabalhos em preparação procurarão alargar o escopo analítico do estudo. 
As escolas da região $\mathrm{N}$ situam-se em áreas pobres da cidade, de baixo valor imobiliário relativo, dispondo de menores recursos de toda sorte, menor acesso a bens e instalações públicas, bem como a oportunidades de cultura e lazer. Contam com grande contingente populacional habitando favelas e enfrentam severos problemas referentes a violência e criminalidade. Estas últimas características, a presença de favelas e os problemas de segurança, dada a especial arrumação geográfica do Rio de Janeiro, podem ser estendidas a praticamente todas as regiões da cidade. Sua intensidade, porém, reduz-se conforme se ascende na hierarquia arbitrada para este estudo. Especialmente no que diz respeito aos equipamentos urbanos, às oportunidades de lazer e cultura e ao peso da classe média na composição social, há clara trajetória ascendente, conforme nos deslocamos sucessivamente às áreas $\mathrm{T}$ (Tijuca e adjacências) e S. ${ }^{14}$ Ressalte-se, porém, que o alunado das escolas municipais e estaduais, no Rio de Janeiro e em quase todo o Brasil, conta essencialmente com estudantes provenientes de segmentos de menor renda, considerando que a "classe média" foi progressivamente se afastando da escola pública em processo histórico coincidente com o ingresso mais acentuado desses setores mais subalternos.

Nenhuma das escolas do estudo fica dentro de comunidades faveladas, mas há alguma diferença nesse aspecto. A escola $\mathrm{N}+$ fica em área bastante degradada, uma região industrial decadente, com muitos prédios abandonados, incrustada entre grandes favelas, temidas por seus índices de criminalidade, um tanto distante de avenidas importantes no deslocamento pela cidade. A escola $\mathrm{N}$ - fica em área igualmente pobre, mas mais próxima de uma grande via de circulação, com muitos recursos de transporte e em local mais "residen-

${ }^{14}$ A divisão geográfica da cidade não está plenamente contemplada por essa categorização aqui estabelecida. Em termos administrativos, há uma classificação bem mais complexa. A área mais afastada do centro econômico da cidade (Zona Oeste) ficou ausente em nosso estudo por força de limites operacionais. No entanto, como os dados demonstrarão, há forte diferenciação nos casos contemplados. cial", mais próxima de estabelecimentos comerciais diversificados. Essas escolas ficam a umà distância menor do que cinco quilômetros entre si.

As escolas da região $\mathrm{T}$, apesar da existência de grande complexo de favelas na região, ficam em área de residência típica de classe média, em vias de grande circulação de veículos e com facilidade de acesso a transportes coletivos. A escola T- fica mesmo dentro de um conjunto de edifícios de classe média. À distância entre ela e a escola $\mathrm{T}+$ não ultrapassa um quilômetro.

As escolas da Zona Sul (S) situam-se em áreas tipicamente "de asfalto", ${ }^{15}$ estando a escola S+em área altamente valorizada da cidade, considerada nobre, com muitas casas e edifícios requintados, ainda que menos servida de transportes coletivos. A escola S- fica em ponto central de uma região totalmente urbanizada, na confluência de vias altamente movimentadas com amplos recursos de deslocamento para qualquer área da cidade. As escolas distam cerca de dois quilômetros entre si.

Do ponto de vista arquitetônico, há alguma disparidade. Todos os prédios escolares dispõem de instalações que podem ser consideradas satisfatórias, ainda que a escola S+ tenha área menor e instalações mais acanhadas, por se situar em prédio que não foi construído com a finalidade de receber uma escola. Salas de aulas e espaços abertos, externos, para recreação ou convivência, em ordem decrescente, são mais favoráveis nas escolas T-, T+, N+e N-, sendo mais exíguos nas escolas da Zona Sul, talvez refletindo a maior valorização do espaço imobiliário na região. Ainda assim, a escola S- dispõe de instalações bem mais adequadas que sua correspondente de maior prestígio ( $\mathrm{S}+$ ). Como se pode observar, não há vantagens nas instalações físicas das escolas de maior prestígio. O mesmo ocorre com as salas de aula e demais espaços de uso pedagógico, como salas de informática. Há, contudo, alguma diferença na conservação e limpeza, ficando as escolas de mais prestígio com aparência interna mais bem cuidada, sobretudo pela ausência de pichações.

${ }^{15}$ Denominação usada vulgarmente na cidade para designar locais contrapostos a favelas. 
Quanto aos aspectos externos, de aparência, as escolas $\mathrm{S}+\mathrm{e} \mathrm{T}+$ ficam em belos prédios antigos, ao passo que as demais dispõem de arquitetura do tipo “caixote", prédios quadrados, fechados, esteticamente pouco atraentes. No período da pesquisa, as escolas da Zona Norte não possuíam mesmo qualquer sinalização externa que as identificasse como estabelecimentos escolares, sinalização bastante usual nas escolas municipais da cidade.

Nas entrevistas com as direções e coordenações das escolas, não encontramos qualquer sinal de existência de tratamento diferenciado quanto à alocação de recursos por parte da administração municipal para as escolas de maior prestígio. Essa era uma forte expectativa quando as selecionamos, pois era de todo desejável que pudéssemos encontrar escolas com possibilidades de recursos equivalentes. Ouvimos, em contrapartida, muito mais queixas por parte das direções das escolas de maior prestígio do que das de baixo prestígio quanto ao tratamento que receberiam da administração municipal superior. Segundo as três direções, o fato de serem escolas "bem resolvidas", que não costumam dar problemas à administração central termina tendo um efeito perverso, que seria a maior quantidade de encargos e menor atenção em geral. É evidente que esses depoimentos podem revelar não exatamente menos atenção para essas escolas, mas uma maior carga de demandas por parte delas.

Uma característica comum às três escolas de alto prestígio é o longo tempo de gestão de suas diretoras. Todas estavam há, no mínimo, 16 anos ocupando a função, ao passo que nas outras escolas as direções estavam, no máximo, há quatro anos no cargo. A maior rotatividade parece ser uma marca dessas escolas de baixo prestígio, também entre o corpo docente, ao passo que nas escolas mais prestigiadas há equipes estáveis, ou núcleos centrais das equipes com vários anos nessas mesmas escolas. A satisfação expressa por algumas professoras inspirou frase ("Aqui é o céu”) ${ }^{16}$ que

16 "Heaven is here - case study of contrasting public schools in Rio de Janeiro" (Costa, 2007). serve de título a trabalho recentemente apresentado em evento internacional.

A frase das professoras parece igualmente sumarizar um sentimento comum que expressaria aquilo que a literatura denomina clima escolar. Duas das escolas mais prestigiadas $(\mathrm{N}+\mathrm{e} \mathrm{T}+$ ) apresentaram nitidamente, na pesquisa qualitativa, resultados coerentes nos questionários com alunos e professores: um forte senso de pertencimento a uma coletividade e de prazer e orgulho por tal pertencimento. Na escola S+ encontramos ambiente mais conflitivo e mais próximo do que pode ser caracterizado como convivência por interesses, menos coesão e menor senso de equipe. Essa foi a escola onde encontramos maior dificuldade de entrosamento e menos espaços de convivência coletiva entre aquelas mais prestigiadas. É possível que nossa observação esteja um tanto influenciada por essa resistência à nossa presença na escola. Porém as ênfases encontradas nessa escola, o que estaria mais próximo da definição de seu projeto coletivo, situar-se-iam em uma linha mais competitiva. Sua direção orgulha-se de afirmar que a escola se dedica a preparar para concursos de acesso a escolas públicas conceituadas ${ }^{17}$ e que grande parte de seus alunos é aprovada para tais escolas. Parece que essa escola adota procedimentos seletivos internos mais rigorosos, contando com taxas de reprovação e abandono mais elevadas que as demais.

Em duas das escolas menos prestigiadas, em nenhum momento encontramos algo que sugerisse um ambiente escolar "positivo" ou o orgulho de pertencimento à escola. São escolas que nos pareceram bastante desagregadas, com docentes e funcionários cumprindo cada um sua tarefa, sem a presença de esquemas aglutinadores e, sobretudo, sem a presença de um sentido ou projeto coletivo que atribuísse sentido superior ao que é feito. Aparentemente, cumpre-se

${ }^{17}$ As escolas públicas mais conceituadas do Rio de Janeiro, no ensino médio, são escolas federais, que existem em proporção maior que nas demais cidades do país, herança de longo tempo em que a cidade foi capital federal. Para tais escolas existem processos seletivos por meio de provas altamente concorridas. 
nelas o que é determinado por instâncias superiores, mais ou menos precariamente.

A articulação dos atores, configurando o "clima escolar", emergiu intimamente vinculada ao papel de lideranças escolares, associando aquelas duas vertentes analíticas apresentadas ao início. O estilo carismático de uma das direções (N+), a que lida com situação social mais adversa, e o estilo mais "racional-legal", mas igualmente propositivo e articulador de sentidos (com núcleo de suporte mais numeroso) observado nas escolas $\mathrm{T}+\mathrm{e} \mathrm{S}+$, não encontraram qualquer semelhança entre as escolas de baixo prestígio. Uma delas, entretanto, parece enfrentar uma situação intermediária, a S-, com uma direção aparentemente bastante atuante, consciente dos muitos problemas, da imagem negativa da escola e preocupada com formular estratégias de reversão desse quadro. Enfrenta, porém, fortes resistências, especialmente entre o alunado da escola, e o resultado parece frustrante - o que nos conduz a reafirmar a idéia de que o prestígio da escola é uma força inercial que tende a fortalecer a trajetória percorrida por ela, como numa metáfora extraída da física.

Essa força inercial entraria como um dos componentes daquilo que vem sendo chamado "círculos viciosos" e "círculos virtuosos" (Brandão, Mandelert $\&$ Paula, 2005) pelos pesquisadores que trabalham com educação de elites. A imagem externa de uma escola seria um elemento que proporciona competição pelo acesso a ela, o que permite algum tipo de seleção por parte de sua burocracia, ${ }^{18}$ no caso de imagens valorizadas. Na contramão, uma imagem externa negativa relega o acesso a tais escolas àqueles providos de menos recursos competitivos ou de menores aspirações (capital cultural?) no campo educacional. Além disso, no plano interno, essa imagem favorece que atitudes positivas ou negativas sejam adotadas pelos diferentes atores, constituindo um elemento cultural relevante que comporia os "círculos" mencionados. ${ }^{19}$

\footnotetext{
${ }^{18}$ Essa seleção no acesso permanece uma das caixas-pretas que desafiam a pesquisa.

${ }^{19}$ Em pesquisa anterior (Educação e exclusão social; o sagrado sob ameaça) observamos fenômeno sugestivo: um aluno
}

Uma possível explicação para a reversão de tal força inercial, quando no caso de um "círculo vicioso", estaria no empuxo de uma figura carismática, conforme os relatos colhidos informam sobre a trajetória de duas das escolas de alto prestígio de nosso estudo. Retornamos, assim, ao papel da liderança escolar, mas não necessariamente em um modelo de causalidade circular, dado que o elemento disparador, em termos históricos, parece estar no plano dos agentes envolvidos.

Com efeito, parece que ao menos em dois dos casos de escolas de alto prestígio estudados $(\mathrm{T}+\mathrm{e}$ $\mathrm{N}+$ ) houve um ponto de inflexão na trajetória de tais escolas. Tal ponto, conforme depoimentos colhidos na intenção de resgatar a história desses estabelecimentos, está associado à entrada das atuais diretoras em seus cargos. Esses processos demandariam uma exposição específica, o que excede as pretensões deste artigo, mas especialmente a escola $\mathrm{N}+$ chama atenção pelo efeito da força carismática exercida por sua diretora.

\section{Alguns resultados do survey com alunos}

A composição de nosso survey, realizado no mês de setembro de 2006, por escola e turma está apresentada na Tabela 1 . No total foram aplicados questionários a 2.650 alunos, tentando cobrir integralmente as turmas das escolas. Há alguma oscilação no número de presentes quando da aplicação dos questionários em virtude do fato de que nos faltavam recursos para efetuar uma aplicação simultânea, conforme seria desejável. Assim, o número de alunos pesquisados pode refletir algum fator fortuito na frequiência em um dia e local específico.

As duas maiores escolas presentes no estudo, em termos de número de turmas e alunos, são S- e N+. As escolas de maior prestígio das Zonas Norte e Tijuca são mais populosas, refletindo um quadro de maior

afirmava sentir muita vergonha de sua escola, feia, muito pichada. Informava, porém, integrar o grupo de pichadores. Todos sabiam disso, mas nenhuma atitude era tomada. 
Tabela 1: Número de turmas e alunos por série, segundo a escola

\begin{tabular}{|c|c|c|c|c|c|c|c|c|c|}
\hline \multirow{3}{*}{$\begin{array}{l}\frac{\pi}{0} \\
\text { U }\end{array}$} & \multicolumn{2}{|c|}{ 5a série } & \multicolumn{2}{|c|}{ 6ª série } & \multicolumn{2}{|c|}{ 7ạ série } & \multicolumn{2}{|c|}{$8^{\underline{a}}$ série } & \multirow[b]{3}{*}{ Total } \\
\hline & $\mathrm{N}$ & $\mathrm{N}$ & $\mathrm{N}$ & $\mathrm{N}$ & $\mathrm{N}$ & $\mathrm{N}$ & $\mathrm{N}$ & $\mathrm{N}$ & \\
\hline & 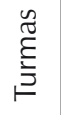 & $\begin{array}{l}\tilde{O} \\
\stackrel{5}{5} \\
\frac{3}{<}\end{array}$ & $\frac{\mathscr{I}}{\stackrel{\Xi}{\Xi}}$ & $\begin{array}{l}\stackrel{n}{0} \\
\stackrel{5}{5}\end{array}$ & 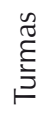 & $\begin{array}{l}\stackrel{n}{0} \\
\stackrel{5}{5}\end{array}$ & 胥 & $\begin{array}{l}\tilde{0} \\
\stackrel{0}{5} \\
\frac{5}{<}\end{array}$ & \\
\hline $\mathrm{N}+$ & 7 & 235 & 5 & 180 & 4 & 140 & 4 & 129 & 684 \\
\hline $\mathrm{N}-$ & 3 & 89 & 2 & 68 & 2 & 46 & 2 & 54 & 257 \\
\hline$T+$ & 4 & 134 & 4 & 128 & 3 & 93 & 3 & 81 & 436 \\
\hline $\mathrm{T}-$ & 4 & 94 & 2 & 56 & 3 & 81 & 2 & 66 & 297 \\
\hline $\mathrm{S}+$ & 3 & 96 & 4 & 121 & 3 & 96 & 3 & 80 & 393 \\
\hline S- & 8 & 219 & 6 & 166 & 4 & 95 & 4 & 103 & 583 \\
\hline Total & 29 & 867 & 23 & 719 & 19 & 551 & 18 & 513 & 2650 \\
\hline
\end{tabular}

procura, contando com turmas mais numerosas, salas mais cheias. As escolas de menor prestígio dessas áreas apresentam algum espaço ocioso, salas não ocupadas por turmas por falta de procura. Já na Zona Sul, a escola S- é bem maior que sua correspondente. De maneira geral, apesar de eventualmente disporem de salas de aula com menores dimensões, as escolas de mais prestígio apresentam maior número de alunos por turma. Em todas as escolas, com exceção da $\mathrm{S}+$, há redução do número de turmas entre a $5^{\mathrm{a}}$ e a $8^{\mathrm{a}}$ série, expressando os fenômenos da evasão e do fluxo escolar truncado. ${ }^{20}$

Essa distribuição por turmas reveste-se de um valor importante em qualquer situação de análise intra-escolar no Brasil (Alves, 2006). Ao organizar as turmas nas séries por faixas de idade de seus alunos, algo bastante usual no Brasil, de fato, após alguns anos de escolaridade, essa distribuição reveste-se de uma forte hierarquização em termos de trajetória escolar pregressa, fortemente associada à hierarquização socioeconômica. Ainda que não haja, nos limites deste trabalho inicial, que se propõe a desenhar um painel geral, possibilidade de explorar mais detidamente essa situação, vale a pena expor a hierarquização etária das turmas por série, conforme a Tabela 2.

${ }^{20}$ Há, ainda, alguma irregularidade na seqüência do número de turmas, em algumas escolas, o que é explicado pelo número de salas disponíveis a cada ano, fazendo com que não haja ingresso do mesmo número de turmas, na quinta série, todos os anos.
Tabela 2: Idade média por escola, segundo a série e a turma

\begin{tabular}{|c|c|c|c|c|c|c|c|c|c|}
\hline 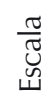 & 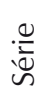 & 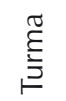 & $\begin{array}{l}\frac{\pi}{\frac{\pi}{7}} \\
\frac{\pi}{2}\end{array}$ & Z & $\begin{array}{l}\frac{\pi}{\tilde{J}} \\
\text { 山 }\end{array}$ & : & 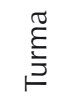 & $\frac{\stackrel{\frac{\pi}{2}}{\frac{\pi}{\pi}}}{\sum^{\frac{\pi}{2}}}$ & Z \\
\hline \multirow[t]{20}{*}{$\mathrm{N}+$} & \multirow[t]{7}{*}{$5^{\underline{a}}$} & 501 & 11,05 & 41 & \multirow[t]{11}{*}{ T- } & \multirow[t]{4}{*}{$5^{\underline{a}}$} & 501 & 11,44 & 34 \\
\hline & & 502 & 11,35 & 38 & & & 502 & 13,15 & 16 \\
\hline & & 503 & 11,20 & 37 & & & 503 & 12,13 & 27 \\
\hline & & 504 & 11,64 & 25 & & & 504 & 13,27 & 17 \\
\hline & & 505 & 11,76 & 39 & & \multirow[t]{2}{*}{$6^{\underline{a}}$} & 601 & 12,53 & 40 \\
\hline & & 506 & 12,12 & 35 & & & 602 & 13,81 & 16 \\
\hline & & 507 & 14,11 & 20 & & \multirow[t]{3}{*}{$7^{\underline{a}}$} & 701 & 13,16 & 28 \\
\hline & \multirow[t]{5}{*}{$6^{\underline{a}}$} & 601 & 11,92 & 40 & & & 702 & 14,13 & 26 \\
\hline & & 602 & 12,19 & 41 & & & 703 & 14,12 & 27 \\
\hline & & 603 & 12,56 & 39 & & \multirow[t]{2}{*}{$8^{\underline{a}}$} & 801 & 14,54 & 39 \\
\hline & & 604 & 13,17 & 33 & & & 802 & 15,19 & 27 \\
\hline & & 605 & 14,73 & 27 & \multirow[t]{13}{*}{$\mathrm{S}+$} & \multirow[t]{3}{*}{$5 \underline{a}$} & 501 & 11,71 & 36 \\
\hline & \multirow[t]{4}{*}{$7^{\underline{a}}$} & 701 & 12,92 & 40 & & & 502 & 11,63 & 30 \\
\hline & & 702 & 13,20 & 44 & & & 503 & 11,48 & 30 \\
\hline & & 703 & 13,91 & 23 & & \multirow[t]{4}{*}{$6^{\underline{a}}$} & 601 & 12,77 & 32 \\
\hline & & 704 & 14,71 & 33 & & & 602 & 12,50 & 32 \\
\hline & \multirow[t]{4}{*}{$8^{\underline{a}}$} & 801 & 14,13 & 41 & & & 603 & 12,59 & 27 \\
\hline & & 802 & 14,21 & 37 & & & 604 & 12,37 & 30 \\
\hline & & 803 & 15,28 & 29 & & \multirow[t]{3}{*}{$7 \underline{a}$} & 701 & 13,23 & 32 \\
\hline & & 804 & 15,57 & 22 & & & 702 & 13,48 & 31 \\
\hline \multirow[t]{9}{*}{$\mathrm{N}-$} & \multirow[t]{3}{*}{$5^{\underline{a}}$} & 501 & 11,17 & 32 & & & 703 & 13,48 & 33 \\
\hline & & 502 & 12,38 & 33 & & \multirow[t]{3}{*}{$8^{\underline{a}}$} & 801 & 14,59 & 23 \\
\hline & & 503 & 13,06 & 24 & & & 802 & 14,69 & 30 \\
\hline & \multirow[t]{2}{*}{$6^{\underline{a}}$} & 601 & 12,53 & 39 & & & 803 & 14,52 & 27 \\
\hline & & 602 & 13,83 & 29 & \multirow[t]{23}{*}{ S- } & \multirow[t]{8}{*}{$5^{\underline{a}}$} & 501 & 10,83 & 33 \\
\hline & $7 \underline{a}$ & 701 & 13,26 & 30 & & & 502 & 11,07 & 31 \\
\hline & & 702 & 15,06 & 16 & & & 503 & 11,47 & 34 \\
\hline & $8^{\underline{a}}$ & 801 & 14,50 & 29 & & & 504 & 11,97 & 34 \\
\hline & & 802 & 15,77 & 25 & & & 505 & 12,52 & 27 \\
\hline $\mathrm{T}+$ & $5^{\underline{a}}$ & 501 & 11,12 & 37 & & & 506 & 12,32 & 22 \\
\hline & & 502 & 11,23 & 36 & & & 507 & 13,56 & 17 \\
\hline & & 503 & 11,94 & 31 & & & 508 & 14,11 & 21 \\
\hline & & 504 & 11,93 & 30 & & $6^{\underline{a}}$ & 601 & 12,04 & 31 \\
\hline & $6^{\underline{a}}$ & 601 & 12,13 & 33 & & & 602 & 12,34 & 34 \\
\hline & & 602 & 12,31 & 32 & & & 603 & 12,88 & 25 \\
\hline & & 603 & 12,38 & 32 & & & 604 & 13,44 & 32 \\
\hline & & 604 & 12,79 & 31 & & & 605 & 14,27 & 23 \\
\hline & $7 \underline{a}$ & 701 & 13,00 & 39 & & & 606 & 14,53 & 21 \\
\hline & & 702 & 13,96 & 24 & & $7 \underline{a}$ & 701 & 12,95 & 22 \\
\hline & & 703 & 13,24 & 30 & & & 702 & 13,44 & 28 \\
\hline & $8^{\underline{a}}$ & 801 & 14,17 & 26 & & & 703 & 14,76 & 22 \\
\hline & & 802 & 14,56 & 32 & & & 704 & 15,04 & 23 \\
\hline & & 803 & 15,00 & 23 & & $8^{\underline{a}}$ & 801 & 14,18 & 30 \\
\hline & & 803 & 12,88 & 25 & & & 802 & 14,85 & 26 \\
\hline & & 804 & 13,44 & 32 & & & 803 & 15,85 & 27 \\
\hline & & 805 & 14,27 & 23 & & & 804 & 15,30 & 20 \\
\hline & & 806 & 14,53 & 21 & & & & & \\
\hline
\end{tabular}


As idades médias nas séries das escolas de alto prestígio são sempre mais baixas que das de baixo prestígio, da mesma forma que os desvios-padrão, indicando sempre escolas com turmas mais jovens nas séries e mais homogêneas. As escolas $\mathrm{S}+\mathrm{e} \mathrm{T}+$, além disso, apresentam perfil etário das turmas indicando também forte homogeneidade entre elas. É possível que essas sejam escolas mais seletivas e com maior nível de "expulsão" de alunos com trajetória escolar irregular. Há, porém uma hipótese alternativa: de que essas escolas consigam imprimir alto desempenho a quase todos os seus alunos, preservando, assim, o ajuste série/idade ao longo de suas séries. Os Gráficos 1 e 2 exprimem respectivamente a mediana de idade nas séries e seus desvio-padrão, por escola.

Esses dados permitiram-nos classificar as turmas das diversas séries, nas escolas, usando a média geral de idade na série como ponto de referência e atribuindo valores 1, 2 ou 3 para uma ordem crescente da idade

Gráfico 1: Idade média por escola, segundo a série

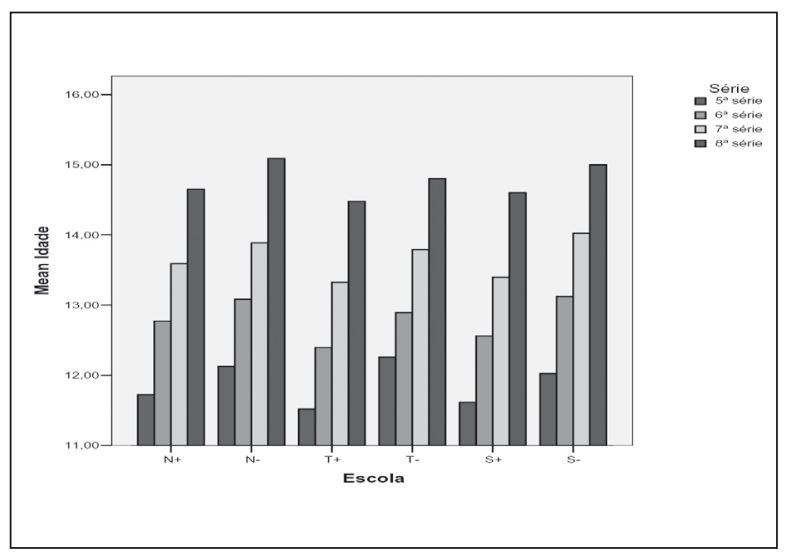

Gráfico 2: Desvio-padrão de idade por escola, segundo a série

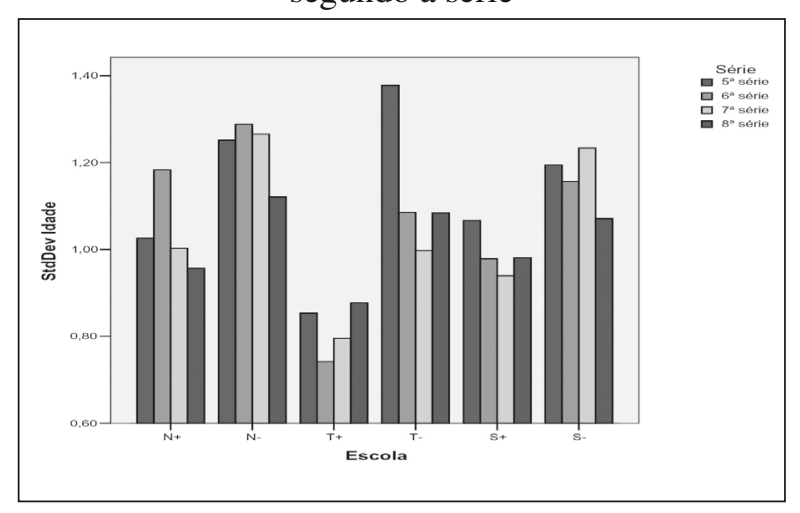

média das turmas, buscando visualizar a maior ou menor homogeneidade de cada escola. $\mathrm{O}$ valor 1 foi atribuído a turmas com idade média abaixo de 0,5 desvio-padrão em relação à idade geral das séries na amostra. $\mathrm{O}$ valor 2 , para idades médias entre $-0,5 \mathrm{e}$ $+0,5$ desvio-padrão, e o valor 3 para idade média na turma superior a $+0,5$ desvio-padrão.

Os valores foram padronizados para melhor visualização dos contrastes (Gráfico 3). Todas as escolas apresentam turmas com valores médios de idade abaixo da média geral da série. Porém, na escola T- praticamente não há turmas com idades médias baixas. Nas escolas de alto prestígio $\mathrm{T}+\mathrm{e} \mathrm{S}+$ praticamente não há turmas com idades médias elevadas. A exceção, como relatamos em vários aspectos, está na escola $\mathrm{N}+$, que apresenta dispersão bem maior, indicando, conforme nossa observação reafirmou, ser menos seletiva socialmente e mais acolhedora em sua dinâmica interna. É possível, porém, que esse fato reflita apenas o fato de ser a maior escola da amostra, contendo inevitavelmente maior diversidade, ou ainda consequiência de estar situada na área mais pobre entre as investigadas. Nossa pesquisa qualitativa, contudo, não caminha nessa direção, pois tende a destacar elementos altamente positivos em termos de inclusão e acolhimento nessa última escola.

O nível socioeconômico das escolas (NSE) foi medido por meio de uma escala de posse de bens domésticos ponderada pela escassez relativa dos bens e posteriormente padronizada. Ainda que não seja uma medida muito precisa, ela mostra clara hierarquização,

Gráfico 3: Idade média da turma da escola, segundo o tipo de turma.

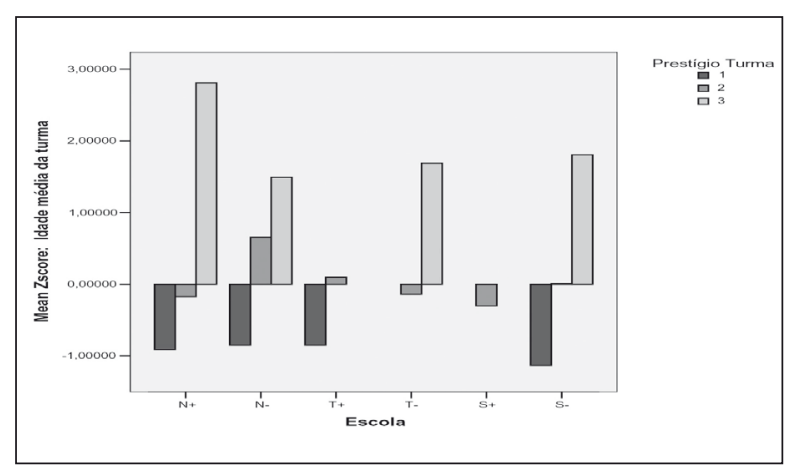


como esperado. O Gráfico 4 apresenta esses dados. Conforme se desloca a medição de Norte para Sul sobe igualmente a medida de NSE. Porém, também se verifica diferença entre as médias de NSE das escolas nas regiões, havendo, contudo, menor distância na Zona Norte (aproximadamente 0,3 dp, contra 0,5 dp nas demais zonas).

\section{Gráfico 4: Nível socioeconômico} (padronizado) por escola

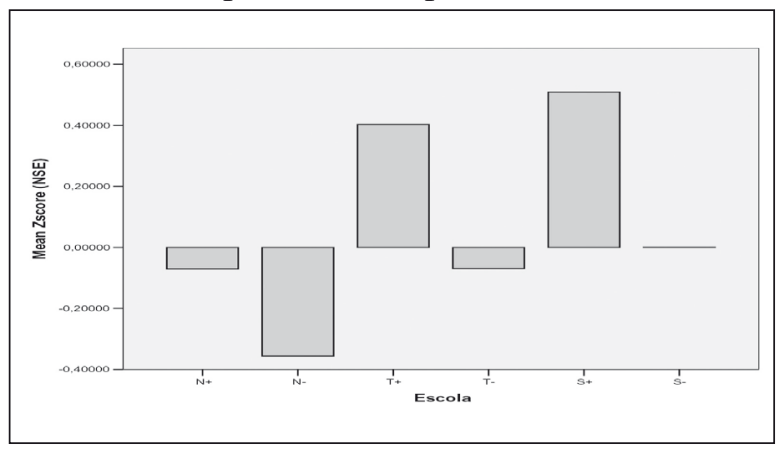

O Gráfico 5 apresenta a distribuição interna do NSE segundo a hierarquia etária das turmas. Observando-as em conjunto, fica clara a hierarquização entre as áreas da cidade e também internamente nas escolas. É interessante observar que o nível socioeconômico acompanha, em razão inversa, a hierarquia etária das turmas e que, para turmas de mesma faixa etária, há vantagens de status socioeconômico para aquelas em escolas de alto prestígio. A escola $\mathrm{N}+$, mais uma vez, destoa um pouco de suas equivalentes nas outras áreas por apresentar perfil mais próximo de seu par de baixo prestígio. Se acrescentássemos um gráfico para escolaridade média das mães, seu desenho seria de enorme

Gráfico 5: Nível socioeconômico por escola, segundo a turma

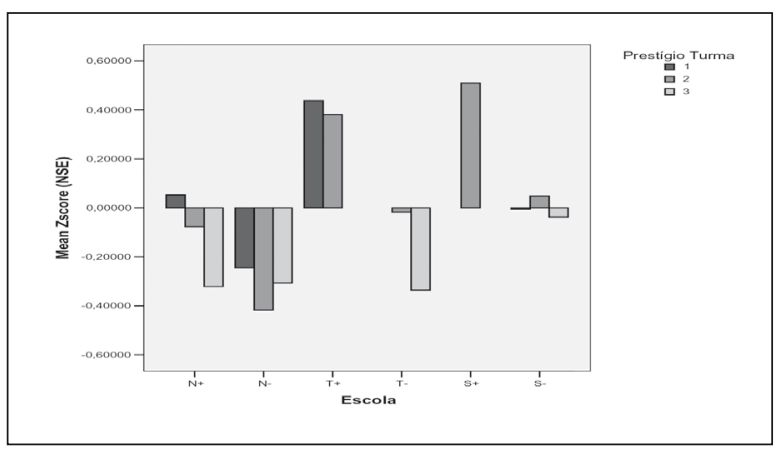

semelhança com os referentes ao NSE. Entretanto, o coeficiente de correlação entre essas variáveis não é tão elevado $(r=0,39)$.

Duas outras diferenças dignas de menção, ainda no plano descritivo das características socioeconômicas e demográficas do alunado, são a formação familiar e a declaração de possuir ou não religião. Esses são fatores destacados aqui por se mostrarem relevantes em modelos analíticos multivariados. Os alunos das escolas mais prestigiadas apresentam diferenças significativas diante de seus colegas das escolas de menor prestígio, estando os primeiros em proporção maior em famílias biparentais ${ }^{21} \mathrm{e}$ declarando ser mais religiosos. As Tabelas 3 e 4 o demonstram.

Tabela 3: Escola x tipo de família

\section{Crosstabulation}

\begin{tabular}{|c|c|c|c|c|c|c|c|}
\hline & \multicolumn{4}{|c|}{ Tipo de família } & \multirow[t]{2}{*}{ Total } \\
\hline & & & $\begin{array}{l}\text { Família } \\
\text { biparenta }\end{array}$ & $\begin{array}{l}\text { Família } \\
\text { Monopa- } \\
\text { renteal }\end{array}$ & $\begin{array}{c}\text { Família } \\
\text { com } \\
\text { padastro/ } \\
\text { madastra }\end{array}$ & $\begin{array}{l}\text { Outros } \\
\text { tipos de } \\
\text { família }\end{array}$ & \\
\hline \multirow{12}{*}{ 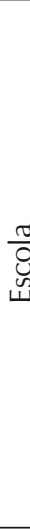 } & \multirow[t]{2}{*}{$N+$} & $\mathrm{N}$ & 406 & 170 & 77 & 31 & 684 \\
\hline & & $\%$ & 59,4 & 24,9 & 11,3 & 4,5 & 100 \\
\hline & \multirow[t]{2}{*}{$\mathrm{N}-$} & $\mathrm{N}$ & 124 & 74 & 37 & 22 & 257 \\
\hline & & $\%$ & 48,2 & 28,8 & 14,4 & 8,6 & 100 \\
\hline & \multirow[t]{2}{*}{$\mathrm{T}+$} & $\mathrm{N}$ & 271 & 113 & 35 & 17 & 436 \\
\hline & & $\%$ & 62,2 & 25,9 & 8,0 & 3,9 & 100 \\
\hline & \multirow[t]{2}{*}{$\mathrm{T}-$} & $\mathrm{N}$ & 169 & 80 & 32 & 16 & 297 \\
\hline & & $\%$ & 56,9 & 26,9 & 10,8 & 5,4 & 100 \\
\hline & \multirow[t]{2}{*}{$\mathrm{S}+$} & $\mathrm{N}$ & 223 & 115 & 34 & 21 & 393 \\
\hline & & $\%$ & 26,7 & 29,3 & 8,7 & 5,3 & 100 \\
\hline & \multirow[t]{2}{*}{ S- } & $\mathrm{N}$ & 259 & 176 & 99 & 49 & 583 \\
\hline & & $\%$ & 44,4 & 30,2 & 17,0 & 8,4 & 100 \\
\hline \multirow{2}{*}{\multicolumn{2}{|c|}{ Total }} & $\mathrm{N}$ & 1.452 & 728 & 314 & 156 & 2.650 \\
\hline & & $\%$ & 54,8 & 27,5 & 11,8 & 5,9 & 100 \\
\hline
\end{tabular}

Quando consideramos diferenças culturais entre os grupos, mais uma vez se confirmam as distinções encontradas. O Gráfico 6 apresenta diferenças de acesso a diversos meios de informação (jornais, revistas, Internet etc.). Os alunos dispunham de escalas ordinais quanto à frequiência de acesso a tais recursos

\footnotetext{
${ }^{21}$ Esse resultado é coerente com o encontrado por Loayza e
} Fukazawa (2006). 
Tabela 4: Escola x "Você tem religião?" Crosstabulation

\begin{tabular}{|c|c|c|c|c|c|}
\hline & \multicolumn{2}{|c|}{ Você tem religião? } & \multirow{2}{*}{ Total } \\
\hline & & & Não & Sim & \\
\hline \multirow[t]{12}{*}{ Escola } & \multirow[t]{2}{*}{$\mathrm{N}+$} & $\mathrm{N}$ & 99 & 585 & 684 \\
\hline & & $\%$ & 14,5 & 85,5 & 100 \\
\hline & \multirow[t]{2}{*}{$\mathrm{N}-$} & $\mathrm{N}$ & 80 & 177 & 257 \\
\hline & & $\%$ & 31,1 & 68,9 & 100 \\
\hline & \multirow[t]{2}{*}{$\mathrm{T}+$} & $\mathrm{N}$ & 59 & 377 & 436 \\
\hline & & $\%$ & 13,5 & 86,5 & 100 \\
\hline & \multirow[t]{2}{*}{$\mathrm{T}-$} & $\mathrm{N}$ & 71 & 226 & 297 \\
\hline & & $\%$ & 23,9 & 76,1 & 100 \\
\hline & \multirow[t]{2}{*}{$\mathrm{S}+$} & $\mathrm{N}$ & 44 & 349 & 393 \\
\hline & & $\%$ & 11,2 & 88,8 & 100 \\
\hline & \multirow[t]{2}{*}{ S- } & $\mathrm{N}$ & 93 & 490 & 583 \\
\hline & & $\%$ & 16,0 & 84,0 & 100 \\
\hline \multirow{2}{*}{\multicolumn{2}{|c|}{ Total }} & $\mathrm{N}$ & 446 & 2.204 & 2.650 \\
\hline & & $\%$ & 16,8 & 83,2 & 100 \\
\hline
\end{tabular}

Gráfico 6: Acesso a informação por escola

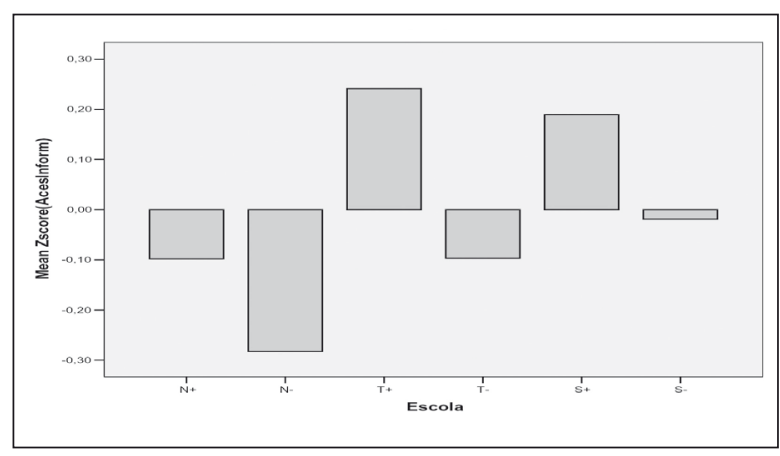

informativos e seus valores, ponderados segundo a escassez relativa, foram padronizados.

Uma análise fatorial (método componente principal) para a freqüência declarada da prática de diversos hábitos ${ }^{22}$ mostrou também marcante diferenciação para o fator intitulado Lazer, por escola e área. A média dessa dimensão extraída está no Gráfico 7. Alunos das escolas mais prestigiadas declaram desfrutar, em média, de mais lazer que seus colegas das escolas

${ }^{22}$ Constavam dessa análise itens de escolha ordinal para frequiência de práticas como estudar, ajudar nas tarefas de casa, ir ao cinema, ir à praia, passear/ir a parques, ver televisão, ir a teatro, encontrar amigos etc. Detalhes técnicos sobre tais itens e sobre a forma como foram tratados na análise fatorial estão disponíveis, aos possíveis interessados, por meio de contato com o autor.
Gráfico 7: Frequiência a atividades

de lazer por escola

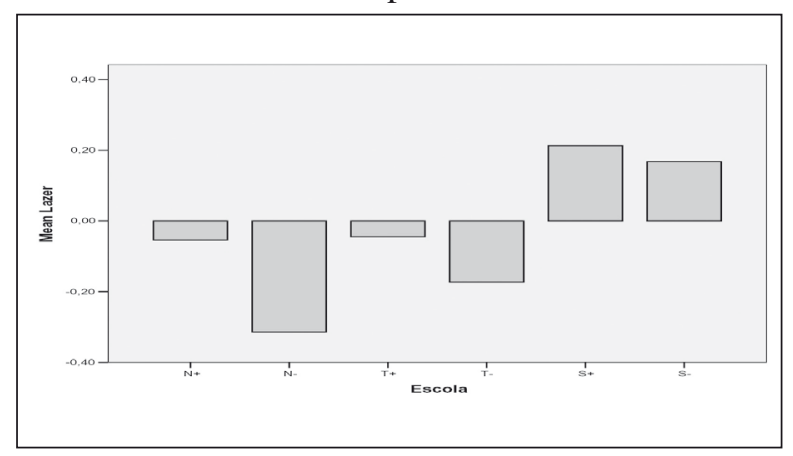

de reputação inferior. $\mathrm{Na}$ Zona Sul, área com maior facilidade de acesso a bens culturais, onde ficam as praias mais acessíveis da cidade e com maior segurança pública, praticamente não há diferenças nas declarações dos alunos das duas escolas. É interessante, e demanda análise mais detida, observar que não foram significativas as diferenças encontradas entre as escolas para o outro fator extraído ("hábitos de estudo/trabalho doméstico"). ${ }^{23}$

Inúmeras informações sobre práticas culturais, opiniões e expectativas foram coletadas e encontramse em análise. A título de exploração, vale expor o resultado de outra análise fatorial construída a partir de notas atribuídas pelos estudantes a elementos que seriam importantes na definição de seus futuros, de acordo com seus desejos. Dois fatores foram extraídos. A um denominamos Fator fortuito, ou seja, ele reduz a um indicador respostas que mostraram estar associadas nesta pergunta ("dar sorte", "conhecer as pessoas certas", "ter boa condição econômica" e "ter boa aparência"). Esse fator pode ser considerado expressivo de uma visão de definição do futuro até certo ponto desvinculada da ação voluntária. Seu contraponto (mas independente) é um fator que denominamos Esforço, por contemplar as variáveis "estudar muito" e "trabalhar duro".

${ }^{23}$ A segunda dimensão extraída da análise fatorial recebeu a denominação Estudo, apesar de contemplar também a "ajuda nas tarefas de casa". Estudos sobre gênero derivados dessa pesquisa devem explorar mais detidamente as importantes diferenças encontradas nesse aspecto. 
É interessante observar como se distribuem esses fatores pelas escolas, apresentando curiosa diferenciação nos valores entre elas - o que pode ser considerado sugestivo da importância de explorarmos mais as diferenças culturais entre esses ambientes. Estudos na linha da cultura institucional podem ajudar na compreensão desses dados. Os Gráficos 8 e 9 mostram a distribuição das médias desses fatores extraídos por análise fatorial segundo as escolas da amostra. A crença em um futuro pessoal condicionado por fatores fortuitos é maior conforme mais pobres são os aglomerados de alunos nos grupos escolares escolhidos. Porém há também diferença considerando os pares de escolas de prestígio contraposto. Já o fator denominado Esforço (Gráfico 9), para os alunos das escolas de maior prestígio, se situa em um patamar comum, mas decresce conforme nos aproximamos das áreas mais "ricas" 24 para as escolas menos prestigiadas.

Gráfico 8: Importância de elementos fortuitos para o futuro por escola

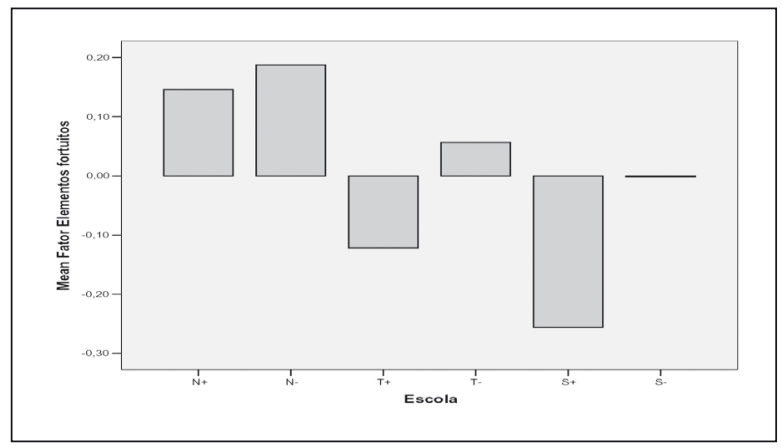

Inquiridos sobre inúmeros aspectos de avaliação de suas escolas, os estudantes respondem de maneira totalmente coerente com o prestígio de suas escolas e turmas, reagindo de forma consistente à oferta $\mathrm{e}$ às oportunidades de que desfrutam. É extremamente rico perceber como a avaliação global das escolas

${ }^{24}$ Em pesquisa anterior, que contemplava também escolas privadas de classe média, o comportamento identificado na escola S- aparecia nessas escolas. Nossa interpretação foi, então, que se tratava de uma condição peculiar da classe média brasileira, além de um certo estilo blasé, que procura demonstrar pouca importância às possibilidades de ascensão social.

\section{Gráfico 9: Importância de esforço} para o futuro por escola

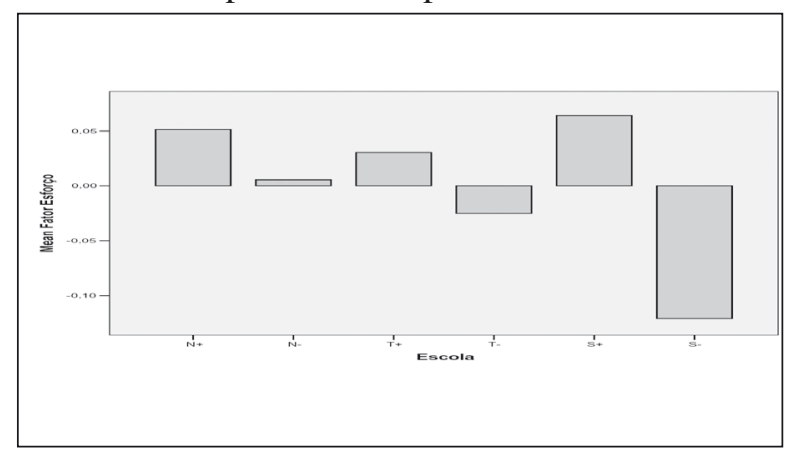

Gráfico 10: Avaliação geral da escola por escola, segundo o tipo de turma
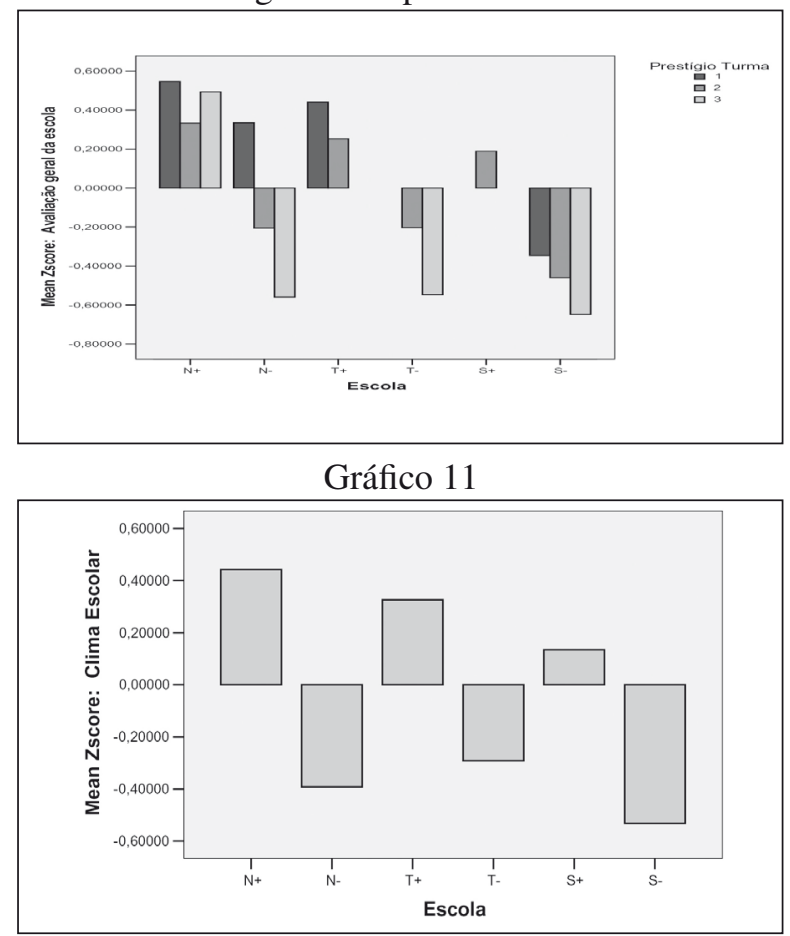

segue uma linha descendente, conforme se eleva a escala social do alunado, possivelmente refletindo as oportunidades de comparação, os termos de referência que os alunos têm quanto aos meios em que convivem. Assim, quando se elevam na hierarquia social da cidade, tendo mais contato com ambientes mais "ricos" em oferta escolar, diminui o grau de satisfação com as escolas públicas. Contudo, a observação in loco faz também pensar que as escolas avaliadas com menor índice de satisfação dos alunos são realmente escolas desagregadas, com ambientes até mesmo hostis para ao menos uma parcela expressiva de seus alunos. 
O Gráfico 10 apresenta essa diferenciação entre turmas e escolas quanto à variável sintética "avaliação geral da escola", construída como um índice a partir de 15 perguntas sobre aspectos específicos da vida escolar. $^{25}$

Uma medida igualmente sumarizada da percepção do "clima escolar", a partir basicamente de perguntas sobre a satisfação de estar na escola e quanto aos relacionamentos com diversos integrantes do ambiente escolar resultou semelhante.

A tentativa de explicar estatisticamente essa avaliação da escola não revelou qualquer componente socioeconômico significativo, destacando, porém, a auto-imagem detida pelos alunos, sua consideração quanto a aspectos de futuro melhor (esforço, fatores fortuitos), seus hábitos de estudo, sua grupalização em turmas e o fato de terem ou não religião. Essa solução resultou de inúmeras tentativas, nas quais mesmo a escolaridade da mãe não obteve nível de significância adequado. Adotamos uma regressão linear múltipla que obteve os seguintes coeficientes $(\operatorname{R} 2 \operatorname{adj}=0,18)$, conforme Quadro 1.

Um modelo para estimação da probabilidade de estar matriculado em uma das escolas de alto prestígio já resultou mais sólido, contemplando as variáveis socioeconômicas e mais variáveis de composição familiar, culturais e volitivas (critérios de escolha da escola). O resultado dessa regressão logística está no Quadro 2.

Por ela observa-se que a escolha da escola por critério de busca de qualidade de ensino aumenta cerca de cinco vezes as chances de estar numa escola desse tipo ou que a escolha pela proximidade da residência reduz à metade tais chances. Ou ainda que a indicação de conhecidos dobra essa possibilidade. Dados relativos ao ambiente social, entre pares, pelo qual circulam também se mostraram significativos,

${ }^{25}$ Foi pedido aos alunos que atribuíssem notas de 1 a 10 para os seguintes aspectos: Organização, Segurança, Disciplina, Professores, Direção, Coordenação, Funcionários em geral, Qualidade do ensino, Limpeza Beleza, Merenda/refeição. Em acréscimo, também foram agregadas respostas padronizadas para itens como "Você gosta da sua escola?", "Você se sente bem nessa escola?" etc.
Quadro 1: Regressão linear para avaliação geral da escola

\begin{tabular}{|l|c|c|c|}
\hline \multirow{2}{*}{\multicolumn{1}{|c|}{ Variáveis }} & $\begin{array}{c}\text { Unstan- } \\
\text { dardized }\end{array}$ & $\begin{array}{c}\text { Standardized } \\
\text { Coefficients }\end{array}$ & \multirow{2}{*}{ Sig. } \\
\cline { 2 - 3 } & B & Beta & \\
\hline (Constant) & $-16,025$ & &, 000 \\
\hline Autoimagem como aluno & 4,793 &, 235 &, 000 \\
\hline Escolaridade da mãe &, 598 &, 039 &, 056 \\
\hline Tem religião & 2,477 &, 055 &, 007 \\
\hline Hábitos de estudo & 2,818 &, 167 &, 000 \\
\hline Prestígio da Turma & $-3,162$ &,- 124 &, 000 \\
\hline $\begin{array}{l}\text { Importância Elementos } \\
\text { Fortuitos }\end{array}$ & 1,435 &, 088 &, 000 \\
\hline Importância Esforço & 2,738 &, 166 &, 000 \\
\hline
\end{tabular}

Obs.: Escolaridade da mãe-> ordinal (1 a 5); Autoimagem como aluno -> Ordinal (1 a 5); Prestígio da turma -> ordinal descendente (1 a 3).

\section{Quadro 2: Regressão logística para a matrícula} em escola de alto prestígio

\begin{tabular}{|l|c|c|}
\hline Variáveis & Sig. & Exp. (B) \\
\hline Escolha: proximidade residência &, 000 &, 490 \\
\hline Escolha: indicação de conhecidos &, 000 & 2,073 \\
\hline Escolha: qualidade de ensino &, 000 & 4,909 \\
\hline Escolaridade da mãe &, 000 & 1,202 \\
\hline Autoimagem como aluno &, 013 & 1,168 \\
\hline Tipo de Família (Categórica) &, 001 & \\
\hline Biparental &, 026 & 1,629 \\
\hline Monoparental &, 516 & 1,162 \\
\hline Outros tipos &, 866 &, 958 \\
\hline Tem religião &, 023 & 1,356 \\
\hline Tem colegas que pararam de estudar? &, 004 &, 902 \\
\hline NSE &, 000 & 1,325 \\
\hline Defasagem para idade média na série &, 000 &, 801 \\
\hline Constant &, 000 &, 177 \\
\hline
\end{tabular}

Obs.: Escolaridade da mãe-> ordinal (1 a 5); Autoimagem como aluno -> Ordinal (1 a 5); Tem colegas que pararam de estudar $->$ ordinal (1 a 5).

na medida em que a pergunta sobre ter colegas que já pararam de estudar (muitos/alguns/poucos/quase nenhum/nenhum) também funcionou no modelo. Em acréscimo, a presença em uma família biparental (Loayza \& Fukazawa, 2006) e a declaração de professar alguma religião elevaram as probabilidades de estar em uma das escolas consideradas de alto prestígio, o que ressalta elementos culturais. Ao lado dos fatores socioeconômicos (NSE e escolaridade da mãe), parece que se compõe um quadro de dimensões interligadas de 
forma complexa que retornam à problematização inicial sobre a formação de "elites". Não são desprezíveis, porém, elementos como o desempenho escolar pregresso e a auto-imagem como aluno, já que surgem com força independente dos demais fatores. Entretanto, modelos experimentados apenas para a Zona Norte indicam que perdem significância e capacidade preditiva as variáveis duras, sugerindo, coerentemente com os dados anteriores e sobretudo com a observação em campo, que é possível haver escolas consideradas de elevado padrão mas pouco seletivas em termos de origem social do alunado.

Entre os desafios de desdobramento desta pesquisa está o aprofundamento dessa linha de investigação: que elementos fazem de uma escola como a $\mathrm{N}+$ uma escola simultaneamente muito querida e prestigiada por todos os seus atores presentes (a que tem melhor avaliação entre os alunos), mas igualmente pouco seletiva em termos socioeconômicos, dado que contempla fortes contrastes internos. ${ }^{26}$

Considerando que o prestígio das escolas deve guardar alguma relação forte com sua capacidade de promover o ensino e a aprendizagem, até que ponto uma escola como a $\mathrm{N}+$ consegue contrariar a conhecida tendência de encontrar eqüidade e qualidade em pratos opostos da balança (Albernaz, Franco \& Ferreira, 2002) no Brasil?

\section{Considerações finais}

Conforme alertado no início, este é um trabalho que reflete a fase inicial de análise dos dados coleta-

${ }^{26}$ Resultados bem recentes, ainda não analisados com apuro, revelam porém que essa escola apresenta, entre as seis da amostra, a mais baixa média de proficiência na Prova Brasil para $8^{\mathrm{a}}$ série. Há hipóteses diversas para tentar explicar esse fenômeno, mas que demandam elaboração própria. A princípio, acreditamos em uma combinação de características menos seletivas e que favorecem a permanência de alunos com desempenho fraco até o fim do ensino fundamental, com achados sobre a baixa expectativa de professores nessa escola quanto a seus alunos e um estilo de gestão que enfatiza aspectos relacionais e de socialização, deixando o desempenho em segundo plano. dos. Usamos também, por ora, um escopo limitado dos dados colhidos, privilegiando dados extraídos de survey com alunos e algumas observações provenientes dos relatos de campo da equipe de trabalho. Por essa razão, optamos por desenhar um retrato abrangente, com inevitável perda de ricas possibilidades de aprofundamento segundo temáticas específicas e adotando modelos mais elaborados de atribuição de causalidade.

Ainda assim, cremos que retratamos um universo complexo com intensa diferenciação quanto a aspectos escolares, mesmo que nos espaços institucionais voltados à população com menores recursos econômicos, típicos das escolas públicas brasileiras. Essa produção e reprodução de hierarquias sociais complexas, vividas e representadas pelos atores presentes se apresenta em expressões colhidas deles. Frases lapidares como "Aqui é bom porque separa as laranjas podres das laranjas boas"27 ou "Vocês vão ficar aqui à tarde? Aí é que vão ver como é. De tarde aqui só tem favelado" ${ }^{28}$ revelam um universo que remete a Norbert Elias e John Scotson (2000) e seu estudo da criação e alimentação de hierarquias em meio a setores sociais que ocupariam posição homogênea, ou quase, em macroclassificações socioeconômicas. Tal quadro é reflexo possível de uma situação de grande competição por poucas oportunidades e por bloqueio nos canais de ascensão, em função da queda acentuada do nível de crescimento econômico do país, desde os anos de 1980. Nesse contexto, as chances de acesso a vias meritocráticas de acesso são fortemente disputadas - ao menos pelo segmento mais informado e com maiores aspirações e recursos - e valorizadas na criação de um sistema simbólico de representação da sociedade que limita as chances de ações coletivas ordenadas em busca de menor desigualdade social.

A busca de um sistema escolar que contemple a distribuição de oportunidades perseguindo padrões de eqüidade sem descuidar da qualidade deve considerar

\footnotetext{
${ }^{27}$ Frase emitida por uma mãe de aluno da escola T+.

${ }^{28}$ Interpelação de um aluno da escola $\mathrm{N}+$, negro, com as-
} pecto pouco cuidado, ao integrante da equipe da pesquisa durante aplicação do survey com alunos. 
esses importantes desníveis, em boa parte construídos pela oferta insuficiente e irregular de escolas públicas que atendam a patamares razoáveis de qualidade. Conhecer em maior profundidade essa realidade é um desafio à pesquisa educacional.

\section{Referências bibliográficas}

ALBERNAZ, Angela; FRANCO, Creso; FERREIRA, Fernando H. G. Qualidade e eqüidade no ensino fundamental brasileiro. Pesquisa e Planejamento Econômico, Rio de Janeiro, v. 32, n. 3, p. 453-476, 2002.

ALVES, Maria Teresa Gonzaga. Efeito-escola e fatores associados à aprendizagem: um estudo longitudinal sobre a produção de hierarquias escolares durante o ensino fundamental. In: ANPOCS. Anais ANPOCS. São Paulo: ANPOCS, 2006.

BALL, Stephen J. Good school/bad school: paradox and fabrication. British Journal of Sociology of Education, Academic Research Library, v. 18, n. 3, p. 317, set. 1997.

BRANDÃO, Zaia. Elites escolares e capital cultural. Boletim Soced PUC-Rio, n. 3, 2006.

; MANDELERT, Diana; PAULA, Lucília de. A circularidade virtuosa: investigação sobre duas escolas no Rio de Janeiro. Cadernos de Pesquisa, São Paulo, v. 35, n. 126, p. $747-$ $758,2005$.

COSTA, Marcio da. Heaven is here - a case study of contrasting public schools in Rio de Janeiro In: New directions in Sociology of Education in/for the 21st Century, 2007, Nicosia. New directions in sociology of education in/for the 21st Century - CD and Book of Abstracts \& Program. Nicosia: International Sociological Association-Cyprus College, 2007.

.; KOSLINSKI, Mariane. Entre o mérito e a sorte - es-

cola, presente e futuro na visão de estudantes do ensino fundamental do Rio de Janeiro. Revista Brasileira de Educação, v. 11, n. 31, p. 133-154, 2006.

DAHL, R. Poliarquia. São Paulo: EDUSP, 1997.

ELIAS, Norberto; SCOTSON, John L. Os estabelecidos e os outsiders: sociologia das relações de poder a partir de uma pequena comunidade. São Paulo: Jorge Zahar, 2000.

LOAYZA, Natasha; FUKAZAWA, Chiharu. La condición conyugal del núcleo: un indicador inestable de las oportunidades de esco- laridad de los adolescentes. 2006. Disponível em: <http://www. siteal.iipe-oei.org>.

NOGUEIRA, Maria Alice. A escolha do estabelecimento de ensino pelas famílias: a ação discreta da riqueza cultural. Revista Brasileira de Educação, São Paulo, v. 1, n. 7, p. 42-56, 1998.

. Élites économiques et excellence scolaire au Brésil: la remise en question d'un mythe. Revue Internationale d'Éducation, Paris, n. 39, p. 67-77, 2005.

.; ALMEIDA, Ana Maria F. (Orgs.). A escolarização das elites: um panorama internacional da pesquisa. Petrópolis: Vozes, 2002.

NOGUEIRA, Maria Alice; ABREU, Ramon C. Escola pública e famílias populares: uma relação dissonante. Educação em Revista, Belo Horizonte, n. 39, p. 41-60, 2004.

SORENSEN, Aage B.; MORGAN, Stephen L. School effects: theoretical and methodological issues. In: HALLINAN, Maureen (Org.). Handbook of the sociology of education. New York: Kluwer Academic/Plenum Publishers, 2000.

WEBER, Max. Economia y sociedad. Ciudad de Mexico: Fondo de Cultura Económica, 1992.

MARCIO DA COSTA, doutor em sociologia pelo Instituto Universitário de Pesquisas do Rio de Janeiro (IUPERJ), é professor da Faculdade de Educação da Universidade Federal do Rio de Janeiro (UFRJ). Publicações recentes: com CUNHA, Marcela Brandão. "Estudantes pobres recém-chegados ao ensino superior: o que pensam os próprios?" (Revista Contemporânea de Educação, v. 3, artigo n. 7, 2007); com KOSLINSKI, Mariana Campelo. "Entre o mérito e a sorte: escola, presente e futuro na visão de estudantes do ensino fundamental do Rio de Janeiro" (Revista Brasileira de Educação, v. 11, n. 31, p. 133-154, 2006); “Criar o público não-estatal ou tornar público o estatal?" (In: ADRIÃO, Tereza; PERONI, Vera. O público e o privado na educação. Interfaces entre Estado e sociedade. São Paulo: Xamã, 2005. p. 13-30). Pesquisas atuais: "Mudança e preservação; estudo de caso sobre processos de alteração de trajetórias em escolas públicas" e "Violência e juventude no Rio de Janeiro”.E-mail: marcioc@pobox.com

Recebido em janeiro de 2008 Aprovado em junho de 2008 
A formação continuada dos docentes no Chile é uma área não regulada pelo Estado. Apesar de sua importância estratégica, reconhecida por todos os atores sociais políticos e institucionais, carece de uma política que ordene e estabeleça um marco regulatório para sua atuação. Esse fato é relevante pela deterioração da educação chilena e porque a reforma dos anos de 1990 parece não haver superado questões-chave nesse sentido; e também porque em suas raízes se encontram a reforma educativa de 1981, que alterou não somente aspectos básicos do sistema escolar, mas também a formação dos professores, cujas conseqüências estão sendo vislumbradas na atualidade. A crise é profunda e debate sobre seu futuro implica contrapor o Estado ao mercado, questão não considerada em alguns debates, mas parece que não há outra opcão senão enfrentá-la na atualidade.

\section{Teacher training in Chile (1990-} 2007): State versus market?

The in-service training of teachers in Chile is a deregulated area of the State, which in spite of its strategic importance, recognized by all social, political and institutional actors, has lacked a policy that orders and provides a regulatory framework in which to act. This phenomenon in Chile is of significant relevance for the general deterioration of education and because the reforms of the 1990's seem not to have solved key questions in this field. Secondly, because its roots are also to be found in the education reform of 1981, which changed not only basic aspects of the school system, but also the training of teachers, whose consequences are now being faced The crisis is deep and the debate on the future implies setting the State in opposition to the market, a question that is avoided in some debates, but for which apparently there is no other option except to face it.
Key words: in-service teacher training; teaching profession; teacher training in Chile

\section{El perfeccionamiento docente en Chile (1990-2007): ¿Estado versus mercado?}

La formación continua de los docentes en Chile es un área desregulada del Estado, la cual pese a su importancia estratégica, reconocida por todos los actores sociales políticos e institucionales, ha carecido de una política que ordene y provea un marco regulatorio para su actuar. Este fenómeno es de relevancia por el deterioro general de la educación y porque la reforma de los años de 1990 parece no haber superado cuestiones claves en este sentido; y también porque en sus raíces se encuentran la reforma educativa del año de 1981, que cambió no solamente aspectos básicos del sistema escolar, sino también la formación de los maestros, cuyas consecuencias se están vislumbrando en la actualidad. La crisis es profunda y su debate sobre el futuro implica contraponer el Estado al mercado, cuestión que se evade en algunos debates, pero pareciera que ya no hay otra opción que enfrentarla.

Palabras clave: formación continua de docentes; profesión docente; formación de docentes en Chile

Marcio da Costa

\section{Prestígio e hierarquia escolar -} estudo de caso sobre diferenças entre escolas em uma rede municipal

Este trabalho explora diferenças entre escolas públicas integrantes da mesma rede de ensino. É parte de um projeto de investigação que busca compreender os elementos que conferem diferenciação a estabelecimentos de ensino que, submetidos à mesma autoridade e às mesmas regras, integrando os mesmos sistemas e dispondo de recursos equivalentes, apresentam considerável disparidade em muitos aspectos e gozam de reputações claramente opostas. Nosso esforço, ancorado em literatura de pesquisa voltada à diferenciação do efeito das escolas (school matters, school effects) e à efetividade escolar (school effectiveness), compõe-se do estudo de caso em seis escolas municipais da cidade do Rio de Janeiro, organizadas em pares, em três diferentes regiões geográficas - e socioeconômicas. Cada par foi escolhido procurando contemplar escolas que usufruem prestígio claramente oposto, localizadas em áreas próximas, podendo atender a populações assemelhadas. Os resultados revelam um complexo sistema de hierarquias socioeconômicas, culturais e educacionais entrelaçadas.

Palavras-chave: prestígio escolar; hierarquias escolares; sociologia da educação

School prestige and hierarchy - a case study on differences between schools in a municipal network This paper explores the differences between public schools which are part of the same educational system. It is part of a research project that seeks to understand the elements which differentiate the quality of educational institutions which, when submitted to the same authority and to the same rules, and integrating the same system and having equivalent resources, present considerable disparity in many aspects and clearly have opposing reputations. Our endeavour, based on research literature directed at the differentiation between schools ("school matters" or "school effects") and school effectiveness, is composed of a case study in six municipal schools of the city of Rio de Janeiro, organized in pairs, in three different geographical and socioeconomic regions of the city. 
Each pair was chosen in the attempt to contemplate schools that clearly posses opposing prestige, located in neighbouring areas, with the capacity to attend similar kinds of people. The results show a complex socioeconomic and cultural differentiation that closely intertwines social and educational hierarchies.

Key words: school prestige; school hierarchies; sociology of education

\section{Prestigio e hierarquía escolar; estudio de casos sobre diferencias} entre escuelas en una red municipal

Este trabajo investiga diferencias entre las escuelas públicas integrantes del mismo sistema de enseñanza. Integra un proyecto investigador que busca hallar los elementos que otorgan diferencias entre los establecimientos de enseñanza que, sujetos a la misma autoridad y a las mismas reglas, integrando los mismos sistemas y disponiendo de recursos equivalentes, presentan diferencias considerables en muchos aspectos y gozan de reputaciones claramente opuestas. Nuestro esfuerzo, amparado en literatura de pesquisa direccionado a la diferencia del resultado de las escuelas (school matters, school effects) y a la efectividad escolar (school effectiveness), se compone del estudio en seis escuelas municipales de la ciudad de Río de Janeiro, organizadas en pares, en tres diferentes regiones geográficas - y socioeconómicas . Cada par fue escogido procurando contemplar escuelas que usufructen de un prestigio claramente opuesto, localizadas en áreas próximas, pudiendo atender a poblaciones semejantes. Los resultados revelan un complejo sistema de jerarquías socioeconómicas, culturales y educacionales entrelazadas.

Palabras clave: prestigio escolar; jerarquías escolares, sociología de la educación

\section{Reinaldo Matias Fleuri}

\section{Rebeldia e democracia na escola}

O pensamento de Michel Foucault ajudanos a compreender os dispositivos de poder disciplinar vigentes na organização escolar que promovem a sujeição dos indivíduos. Ajuda-nos também a entender os processos de resistência expressos por vezes em ações de rebeldia individual ou coletiva. $\mathrm{O}$ artigo busca entender pela óptica da complexidade (Gregory Bateson) e na perspectiva pedagógica de Paulo Freire e de Céléstin Freinet - como trabalhar com as manifestações de rebeldia, na direção de uma prática educativa emancipatória, dialógica e democrática. As práticas de transgressão podem constituir as bases para processos educativos que superem as relações de saber-poder disciplinar, na medida em que forem assumidas coletivamente (consolidando relações de reciprocidade e solidariedade) e ativamente (cultivando a diversidade de iniciativas e interações). Para isso, é preciso desvencilhá-la do caráter de delinqüência que lhe é impingido pelo sistema examinatório de vigilância e sanção.

Palavras-chave: poder disciplinar; rebeldia; complexidade; diálogo; exame

\section{Resistance and democracy in the school}

Michel Foucault's thinking helps us to understand the disciplinary power apparatus in the school system, which promotes the subjection of the individual. It also helps us to understand the processes of resistance, sometimes expressed in individual or collective acts of rebellion. This article seeks to understand-from the perspective of complexity (Gregory Bateson) and from Paulo Freire's and Céléstin Freinet's pedagogic perspective - how to work with manifestations of resistance aiming at an emancipating, dialogic and democratic educational practice. The practice of transgression may constitute the bases for educational processes that can overcome the disciplinary knowledge-power relationships, as they are collectively (consolidating relations of reciprocity and solidarity) and actively assumed (cultivating the diversity of initiatives and interactions). For this, it is necessary to disentangle it from the label of delinquency which is forced upon it by the examination system aimed at surveillance and punishment.

Key words: power apparatus; resistance; complexity; dialogue; examination system

\section{Rebeldía y democracia en la escuela} El pensamiento de Michel Foucault nos ayuda a comprender los dispositivos de poder diciplinar vigentes en la organización escolar, que promueven el sometimiento de los individuos. Nos ayuda también a entender los procesos de resistencia expresos por veces en acciones de rebeldía individual o colectiva. El artículoa busca entender - en la óptica de la complejidad (Gregory Bateson) y en la perspectiva pedagógica de Paulo Freire y de Céléstin Freinet - como trabajar con las manifestaciones de rebeldía, en la dirección de una práctica educativa emancipadora, dialógica y democrática. Las prácticas de transgresión pueden constituír las bases para procesos educativos que superen las relaciones de saberpoder diciplinar, en la medida en que sean asumidas colectivamente (consolidando relaciones de reciprocidad y solidariedad) y ativamente (cultivando la diversidad de iniciativas e interaciones). Para eso, es preciso desvencijarla del carácter de delincuencia que le es impuesto por el sistema examinador de vigilancia y sanción.

Palabras clave: poder diciplinar; rebeldía; complexidad; diálogo; examen 